\title{
SEXUALIDADE NA ADOLESCÊNCIA: UM ESTUDO BIBLIOGRÁFICO
}

\author{
Maria Aparecida Tedeschi Cano* \\ Maria das Graças Carvalho Ferriani** \\ Romeu Gomes***
}

\begin{abstract}
CANO, M.A.T.; FERRIANI, M.das G.C. Sexualidade na adolescência: um estudo bibliográfico. Rev.latinoam.enfermagem, Ribeirão Preto, v. 8, n. 2, p. 18-24, abril 2000.
\end{abstract}

Esta é uma pesquisa bibliográfica onde se buscou construir a história da sexualidade através dos tempos e as influências culturais, sociais e religiosas nessa trajetória. Nosso objetivo foi o de buscar na literatura as raizes das dificuldades enfrentadas pelos homens de nossos dias para abordar temas relacionados à sexualidade principalmente junto aos filhos adolescentes que necessitam dessa orientação para viver uma sexualidade com segurança e também mais saudável.

UNITERMOS: sexualidade, adolescência

\section{INTRODUÇÃO}

Os profissionais de saúde que se propõem a trabalhar com grupos de adolescentes nas Unidades Básicas de Saúde, Escolas ou Centros Comunitários, sabem que a questão que emerge com muito significado nas discussões é a sexualidade.

Como enfermeiras, desenvolvendo atividades de orientação sexual junto a grupos de adolescentes nas escolas ligadas ao Programa de Saúde Escolar (PROASE) em Ribeirão Preto-SP, temos vivenciado a experiência de abordar assuntos como a gravidez, a contracepção, as DST/AIDS, o homossexualismo, a masturbação e o "ficar", entre outros, e que nos levam a repensar nossos valores e atitudes frente a estas questões.

Por outro lado, sabemos que os adultos que cercam o adolescente, pais e professores, têm dificuldade para abordar essa temática no dia-a-dia, não permitindo com isso que os jovens tenham uma fonte segura, principalmente nos dias atuais, para esclarecer suas dúvidas.

Segundo OSÓRIO (1992), a adolescência é uma etapa da vida na qual a personalidade está em fase final de estruturação e a sexualidade se insere nesse processo sobretudo como um elemento estruturador da identidade do adolescente.

Daí a necessidade de buscarmos conhecer melhor os mitos, tabus e a realidade da sexualidade para que possamos abordá-la de forma mais tranqüila com os adolescentes, de manter um diálogo franco e entender as manifestações dessa sexualidade aflorada e própria da idade.

O sexo tornou-se um dos assuntos mais discutidos nos tempos modernos, embora Freud, já nos fins do século passado, tenha escrito e debatido muitas questões relativas à sexualidade e ao comportamento sexual. Sua filosofia tem sido amplamente divulgada e incrementada no mundo atual, pois a sociedade vem passando por profundas transformações desde a II Guerra Mundial, ressaltandose que, neste último século, a mulher adquiriu uma "liberdade sexual" e social totalmente desconhecida há três gerações.

Em seu novo papel de mulher, independente, tem competido em muitos terrenos com o homem e tem ocupado cada vez mais seu lugar, quer seja nas artes, na literatura, na indústria ou nos esportes.

Essas transformações culturais e morais acarretaram inúmeros problemas sociais novos ou agravaram outros já existentes como: prostituição, aborto, homossexualidade, desajustes conjugais, divórcio e outros. Com isso, a "célula" da sociedade que é a família sofreu sérios abalos, o que fez com que pesquisadores e cientistas estudassem o problema da sexualidade de forma profunda, reformulando conceitos e respondendo aos problemas de relacionamento sexual através de inúmeros textos científicos.

É nosso objetivo, neste estudo buscar na literatura as raízes das dificuldades enfrentadas pelos homens de

\footnotetext{
* Professor Associado do Departamento de Enfermagem Materno-Infantil e Saúde Publica da Escola de Enfermagem de Ribeirão Preto da Universidade de São Paulo

** Professor Titular do Departamento de Enfermagem Materno-Infantil e Saúde Pública da Escola de Enfermagem de Ribeirão Preto da Universidade de São Paulo

*** Doutor em Saúde Pública, Pesquisador do Instituto Fernandes Figueira da FIOCRUZ
} 
nossos dias para abordar temas relacionados à sexualidade e os contornos que esta assumiu em diferentes épocas e civilizações.

\section{A SEXUALIDADE ATRAVÉS DOS TEMPOS}

Nos primórdios da civilização, segundo as teorias de ENGELS (1982), as atividades sexuais eram livres entre homens e mulheres, sem que isso tivesse uma conotação de promiscuidade. Os filhos descendiam da linhagem materna, pois só se sabia com certeza quem era a mãe, e os grupos familiares formavam os clãs.

Essa forma de relacionamento livre foi se transformando com o passar do tempo em conseqüência do acúmulo de bens nos clãs, surgindo as primeiras propriedades privadas. Com essa nova forma de organização social, o relacionamento sexual passou a ser atividade exercida por um casal, para que seus filhos legítimos pudessem herdar os bens desse clã. Os casamentos foram se tornando monogâmicos e as famílias se organizaram dentro do sistema patriarcal, com linhagem sangüínea paterna.

Nessa forma de organização familiar, o sexo passa a ter como objetivo a reprodução; as mulheres se tornam submissas aos maridos, a quem se mantêm fiéis sexualmente; o mesmo não ocorre com os homens que podiam manter atividades sexuais fora do casamento.

Em COSTA (1986) encontramos que a nossa civilização ocidental tem suas raízes entre o povo hebreu, de quem foram herdados os princípios morais, legais e religiosos. Os hebreus adotavam a forma patriarcal de casamento e o consideravam de cunho divino. Da mulher era exigido que se mantivesse virgem até o casamento e a castidade de homens e mulheres era exaltada.

Entre os gregos, a função reprodutiva também era a mais importante no casamento, uma vez que havia necessidade de homens para as infindáveis guerras de conquistas de novos territórios. As meninas eram educadas para as tarefas domésticas e preparadas para se casarem logo após as primeiras menstruações e geralmente com homens mais velhos. Os meninos, ao contrário, eram desestimulados ao casamento antes dos 21 anos de idade e as masturbações eram condenadas pelo medo do enfraquecimento e perda de energia. No entanto, o homossexualismo era estimulado, mas somente com os mestres responsáveis pelo desenvolvimento moral e intelectual dos jovens aprendizes, até que estes terminassem seus estudos.

Os romanos assimilaram grande parte da cultura grega e a riqueza do vasto império dos césares permitia festas suntuosas para a elite dominante, onde o prazer sexual era apenas parcialmente restrito.
Segundo GAUDERER (1994), as regras foram surgindo como mitos e tabus para estabelecer limites ao sexo. Um exemplo era o tabu do incesto, cuja finalidade era evitar a mistura de material genético de pessoas consangüíneas, o que poderia acarretar uma deterioração da espécie. Da mesma forma, o uso de roupas cobrindo partes eróticas e sensuais do corpo tinham como objetivo não estimular eventuais parceiros.

Por outro lado, os tabus e mitos a respeito da masturbação, sexo anal e homossexualismo originaramse exatamente por não se tratarem de atividades procriativas, pondo em risco a perpetuação da espécie, segundo o autor citado, esses mitos surgiram numa época em que a sobrevida do ser humano girava em torno dos 30 anos e havia necessidade de homens para as guerras, lavouras e para o trabalho.

COSTA (1986), ressalta que a sexualidade dentro da concepção religiosa é carregada de tabus que afetam a maneira de se encarar a sexualidade, e o primeiro deles refere-se ao "pecado" de Adão e Eva, a partir do qual, tudo o que diz respeito ao relacionamento sexual está ligado a um sentimento "de vergonha". Outros tabus são os de que os anjos são assexuados e portanto puros, e o diabo representa a sexualidade vivida em promiscuidade; todos eles atestam uma atitude desfavorável da igreja com relação ao sexo e ao prazer.

CABRAL (1995), acrescenta uma outra idéia repassada pela doutrina cristã no ocidente, que é a dualidade entre corpo e alma, na qual a alma é mais importante que o corpo, pois a mesma recebeu de Deus a existência e a imortalidade. Essa idéia favoreceu uma educação sexual que nega o corpo ou o coloca em segundo plano. Ao longo da história ocidental, esta tem sido uma forma de os homens viverem a sexualidade de maneira reprimida.

De uma certa forma, segundo COSTA (1986), as normas, os valores cristãos e as necessidades do Estado foram enquadrando a sexualidade, principalmente a partir do século XVI, quando se inicia o processo de modernização da sociedade e a ascensão da burguesia, aliando as influências da Igreja e dos moralistas no controle da vida social.

Podemos acrescentar ainda que, nesse final de século, o poder da ciência e da tecnologia vem ditando novas regras, estabelecendo permissões e proibições para os relacionamentos sexuais.

Até aqui vimos como a sexualidade foi fortemente influenciada pelas idéias cristãs, culturais, políticas e econômicas, nas quais a iniciação sexual da mulher deveria se dar no casamento e ter fins procriativos, enquanto ao homem eram permitidas a prática sexual e a busca do prazer fora dos limites do matrimônio.

A partir do século XVIII, na Europa, como nos aponta GIDDENS (1993), surge o amor romântico, que 
vincula a idéia de liberdade para a busca do parceiro ideal, considerado um aspecto desejável no matrimônio.

O amor romântico, juntamente com outras mudanças sociais, afeta a visão sobre o casamento até então e suscita a questão de compartilhar, de intimidade do casal e ajuda a separar o relacionamento destes outros aspectos da organização familiar. O sexo se une ao amor e começa a fazer parte do casamento, dada a possibilidade de escolha do parceiro.

Durante muitas décadas, o amor romântico manteve-se associado ao casamento e à maternidade, reforçando a idéia de que o verdadeiro amor uma vez encontrado é para sempre.

\section{A SEXUALIDADE NO BRASIL}

Na sociedade brasileira, em virtude da influência portuguesa em nossa colonização, a sexualidade dentro do casamento não se deu de forma muito diferente da que aconteceu na Europa.

Para GOLDBERG (1984), no Brasil-colônia a Igreja Católica, para combater o concubinato (forma de união predominante nas camadas rurais e populares), defende a família patriarcal, como o principal modelo de poder na organização familiar, em que só se admitia o desejo e o prazer sexual do homem fora do lar com prostitutas ou mulheres pobres (brancas, negras, índias e mestiças), por isso elas se tornavam a companheira sexual preferida para o homem branco e também para a iniciação sexual dos meninos.

A esposa, geralmente portuguesa ou espanhola, tinha uma posição social de destaque, mas, estava confinada a um mundo anti-sexual. A sexualidade para ela resumia-se à reprodução da raça e essa era a educação passada de mãe para filha.

Segundo a autora, o Brasil tornou-se uma República mas a diferenciação não desapareceu, principalmente nas grandes cidades onde o maior contingente de mulheres para o prazer sexual são provenientes das classes pobres, mostrando que as raízes classistas e raciais não desapareceram.

Para PARKER (1991), o patriarcalismo no Brasil não foi simplesmente uma forma de organização familiar e social, foi também uma construção ideológica, onde os conceitos de homem e mulher foram definidos em termos de oposição; o homem como um ser forte, superior, ativo, viril e com potencial para violência; e, em contrapartida, a mulher como um ser inferior em todos os sentidos: mais fraca, dócil, bela e desejada, mas de qualquer forma, e em qualquer posição social, sujeita à absoluta dominação masculina.

Ainda para o citado autor, "Essa extrema diferenciação carregava consigo um dualismo moral explícito, que contribuiu para legitimar e reforçar a ordem aparentemente natural de hierarquia de gênero" (p.58). Esse legado patriarcal continua a afetar o pensamento brasileiro e a maneira como os homens de hoje visualizam seu meio social.

Por outro lado, CONCEIÇÃO (1988) afirma que, tanto para homens como para mulheres, a educação sexual sempre foi ostensivamente repressora. As regras sociais vigentes só aceitavam, para os jovens, o exercício da sexualidade dentro do matrimônio e mesmo assim limitado à reprodução.

Esse esquema se manteve estável até meados da década de 50, quando se desencadeou, na Europa, o "movimento beat" com reflexos no Brasil. Esse movimento, representando uma contestação dos jovens ao modelo social vigente, trazia em seu bojo a "revolução sexual", pregando uma nova concepção de sexo desvinculado de compromisso, o uso de drogas e novos hábitos de vestir e falar.

Segundo a autora, esse movimento trouxe a oportunidade para que o homem avaliasse seu comportamento sexual e repensasse a opressão que vinha vivendo há várias gerações.

Na década de 60, segundo SALES (1988), um outro movimento começa a tomar vulto, o "movimento hippie", que surgiu como uma grande esperança de derrubada de muitos mitos políticos, culturais, sociais e entre eles os sexuais, como o da virgindade e da superioridade masculina. Novos conceitos começam a ser discutidos como o direito ao prazer sem restrição, a liberação sexual da mulher através da pílula anticoncepcional e a produção, em larga escala, de revistas pornográficas.

Segundo CONCEIÇÃO (1988), vários estudos sobre sexualidade foram iniciados mostrando que a sociedade vigente desvinculava o sexo da natureza humana. O homem, apesar de acreditar no seu direito de buscar o prazer e o seu exercício pleno, vivia em conflito entre esses ideais de liberdade e uma educação sexual rígida da qual era fruto.

O exercício da sexualidade por homens que foram educados sob repressão, não lhes dava liberdade e nem sempre trazia benefícios, podendo mesmo haver prejuízos e cita como exemplos mais relevantes dessa situação o uso do sexo para agredir o sistema, o sexo com finalidades econômicas, além de sua exploração e vulgarização pelos meios de comunicação de massa.

\section{OS PAIS FRENTE A SEXUALIDADE DOS FILHOS ADOLESCENTES}

Os pais da década atual foram os adolescentes desse período de transformações e vivenciaram, de 
diferentes maneiras, esses movimentos que influenciaram suas visões de mundo e, de uma certa forma, os deixaram inseguros vendo os rígidos padrões morais de sua infância irem sendo derrubados pelas rápidas transformações que estavam ocorrendo, sem que houvesse um tempo para a elaboração e modificação da realidade interna de cada um (SALES, 1988).

Segundo TIBA (1986), é inegável que essas experiências produziram adultos de um tipo especial, que se consideram psicologizados, pois levam em conta que nem sempre as relações humanas obedecem a regras sociais; muitas vezes elas são movidas por desejos. Querem que os filhos sejam mais felizes do que eles próprios, mas não estão seguros de como transmitir isso.

Para o autor, talvez a principal explicação para esse antagonismo é que o discurso liberal e a psicologização instalou-se na superfície, na periferia da personalidade desses pais, ao passo que a educação e os valores que receberam durante a infância e juventude permanecem gravados, quase intactos, numa região mais profunda de sua personalidade.

Essas "camadas", a periférica e a profunda se alteram durante o período de educação dos filhos. Quando chega a adolescência e se apresentam questões mais sérias, como é o caso da sexualidade, a camada mais profunda entra em ação e eles acabam, repetindo as mesmas atitudes que condenaram em seus pais.

Segundo SUPLICY (1991), a questão da sexualidade mudou tão rapidamente, nas últimas décadas, que deixou os pais meio perdidos. Antigamente as famílias não tinham muitas dúvidas em saber o que era certo ou errado; o que podiam permitir ou não. Hoje vivemos um momento difícil para a construção de um sistema de valores sexuais.

Para a autora, apesar do período de transição em que vivemos, existem alguns valores que não podem deixar de ser transmitidos aos jovens, tais como:

1. O respeito por si próprio e pela sua dignidade enquanto pessoa.

2. O respeito pelo outro. A ninguém é permitido ver outro como meio de satisfação de suas necessidades.

3. O acesso à informação. Responder o que a criança quer saber de forma honesta e não preconceituosa.

4. Ajudar a criança a desenvolver o espírito de crítica, a capacidade de raciocínio e a reflexão para escolher o que lhe convém.

Um outro aspecto da sexualidade abordado por SUPLICY (1991) é que, para lidar com a sexualidade dos filhos, os pais necessitam se defrontar com a própria sexualidade e esta situação pode gerar, muitas vezes, angústia. A sexualidade dos filhos traz à tona para muitos pais aspectos reprimidos da própria sexualidade.

Uma pesquisa realizada por ARRUDA (1992) nas escolas públicas e privadas de Campina Grande -
Paraíba, com adolescentes entre 13 e 19 anos, deixa evidente, através das respostas aos questionários aplicados, que os jovens se ressentem da falta de informações sobre sexo. No entanto, esses mesmos jovens citam que a primeira fonte de informação são os amigos e as revistas "Ele e Ela, Playboy e Privê" (especialmente os meninos). As orientações recebidas em casa, segundo a autora, não esclarecem nada, uma vez que os jovens só ouvem de seus pais frases como: "sexo só quando casar"; "isto é pecado"; "é feio".

Apesar da dificuldade dos pais, entendemos que é no convívio familiar, entre pessoas que se estimam e tentam superar as dificuldades do dia a dia que as questões de sexualidade devem ser debatidas levando-se em conta os valores, atitudes, crenças religiosas e culturais da família.

\section{ADOLESCÊNCIA E SEXUALIDADE}

Como afirma PARKER (1991), "cada vez mais, a sexualidade tem sido tema de discussão e debate não apenas na sociedade brasileira e sua importância fica ainda mais pronunciada quando controvérsias sobre o aborto, os direitos das minorias sexuais e, mais recentemente, a alarmante propagação da AIDS se colocaram no centro das atenções pública na vida contemporânea". (p.17)

Em SUPLICY et al. (1995), encontramos que a AIDS é uma epidemia mundial e seu combate só será possível através de um trabalho de prevenção e conscientização da necessidade de se mudar comportamentos sexuais até agora aceitos como corretos.

Segundo os autores, a população e principalmente os adolescentes necessitam ser esclarecidos de que o vírus da AIDS não está mais circunscrito aos chamados grupos de risco, mas envolve a todos, independente de classe social, raça, sexo, idade, crença religiosa, desde que não se protejam em seus relacionamentos sexuais.

Os autores citados colocam que muitos obstáculos culturais e emocionais ainda dificultam o trabalho de prevenção não apenas da AIDS, como também das Doenças Sexualmente Transmissíveis. Dentre os obstáculos apontados pelos autores gostaríamos de ressaltar o da "onipotência", um sentimento próprio dos adolescentes e que os levam a imaginar que com eles "nunca vai acontecer" e que estão imunes a qualquer perigo. "Assim eles se colocam diante do HIV, acreditando que não pegam AIDS e, portanto, não são necessários comportamentos preventivos como o uso da camisinha..." (SUPLICY et al., 1995, p. 86).

Ao lado de questões como a AIDS e as doenças sexualmente transmissíveis, a sociedade, em crescente 
transformação de valores e padrões culturais, está convivendo com a realidade de uma iniciação sexual cada vez mais precoce entre os jovens. Segundo RAPPAPORT (1995), "por muitas razões (falta de comunicações, cobrança dos grupos, mensagens transmitidas e incentivadas pelos meios de comunicação de massa, falta de diálogo com os pais, solidão, etc.), é freqüente o inicio de uma vida sexual precoce" (p. 48).

Para essa autora, quando um jovem está desestruturado e cede a essas pressões, as relações sexuais costumam trazer muito mais angústias do que prazer.

A iniciação sexual precoce entre adolescentes tem acarretado uma preocupação cada vez maior entre profissionais de saúde, pais e professores em decorrência da falta de conhecimentos sobre concepção e uso de contraceptivos.

LOPES \& MAIA (1993) referem-se a uma tendência na diminuição da idade da primeira relação sexual. No Brasil, a idade média é de 16,9 anos para meninas e 15 anos para os meninos, sendo que essa iniciação precoce não vem acompanhada de cuidados com a anti concepção. Segundo esses autores, 26\% da população feminina de 15 a 24 anos já viveu uma gravidez, sendo que a mesma foi indesejada para $40 \%$ dessas jovens.

Em reportagem da Folha de São Paulo, encontramos que a Organização Panamericana de Saúde (OPS) estima que anualmente 1,2 milhão de adolescentes provoquem aborto no Brasil, o que significa que quase a metade daquelas que engravidam acabam abortando. Estes dados nos apontam o despreparo dos jovens para assumirem uma vida sexual, gerando sérios problemas físicos, emocionais e sociais (UM MILHÃO...,1991).

Cabe ressaltar que atualmente as famílias vêm se deparando com inúmeras mensagens de apelo sexual nos meios de comunicação e como apontam LOPES \& MAIA (1993) o corpo e a sexualidade têm sido usado exaustivamente para divulgar e vender "desde sabão em pó até toalhas de banho", tornando-se produto consumível.

Essa banalização da sexualidade tem dificultado a tarefa de educar, de associar sexo a afeto, responsabilidade e promoção da saúde.

Diante dessa realidade, a sexualidade deve ser um tema de discussão e debate entre pais, educadores e profissionais de saúde, tendo como objetivo encontrar maneiras de informar e orientar os jovens para que protelem ao máximo sua iniciação sexual, tenham responsabilidade, auto-estima e pratiquem sexo com segurança.

A sexualidade é um dos importantes aspectos da adolescência, muito enfatizado não apenas pelos dados já apontados, mas também por que é nessa fase da vida do ser humano que a identidade sexual está se formando.
Segundo KNOBEL (1992), a partir do nascimento de uma criança em nossa sociedade, a família já começa a diferenciá-la sexualmente através de roupas, cores, brinquedos e objetos. Os pais sutilmente se encarregam de ir impondo, durante a infância, as diferenças entre meninos e meninas e a sociedade trata de acentuá-las mediante elementos meramente externos. Mas, a definição da identidade sexual só se dará ao longo de um complexo processo bio-psicológico e social, no qual as atitudes da família influem de maneira determinante.

De acordo com EGYPTO et al. (1991), a família vai influir de forma determinante nos papéis sexuais dos filhos, por que a nossa sociedade ainda demarca os papéis sexuais de forma rígida e esteriotipada. "O tabu que pesa sobre a iniciativa sexual das mulheres, por exemplo, tem muito a ver com o papel de subordinação que a sociedade estabelece para o sexo feminino" (p.50).

Os autores colocam, ainda, que esses padrões de comportamento já começam a ser questionados pelas gerações mais jovens, mas pais e educadores nem sempre se dão conta de que continuam a perpetuar os velhos padrões de comportamento destinados socialmente a meninos e meninas.

Apesar de desde o nascimento, meninos e meninas já estarem recebendo mensagens sobre seu papel sexual na sociedade e virem construindo sua identidade, KNOBEL (1992) aponta que é a partir do instante em que o indivíduo se integra à sua genitalidade, que esta passa a dominar sua conduta e aspirações.

Entrar no mundo adulto, desejado e temido ao mesmo tempo, significa para o adolescente ir, gradativamente, se desprendendo de sua condição de criança. Este é considerado o momento crucial na vida do homem, pois constitui a etapa decisiva de um processo que começou com o nascimento.

As mudanças físicas correlacionadas com as mudanças psicológicas levam o adolescente a uma nova relação com os pais e com o mundo, mas isto só será possível se o adolescente puder elaborar lentamente os vários lutos pelos quais passa, ou seja, o da perda do corpo infantil, a perda dos pais na infância e a perda da identidade infantil. Quando o adolescente vive todo esse processo, ele se inclui no mundo com um novo corpo já maduro e uma imagem corporal formada, que muda sua identidade, e é esta a grande função da adolescência, a busca da identidade que ocupa grande parte de sua energia.

Entendemos, a partir da literatura, que a parceria escola-família-saúde seria uma das alternativas para se buscar "maneiras" de orientação sexual aos adolescentes, facilitando a tarefa educativa de pais e professores.

Em síntese, entendemos que a tarefa de educar e transmitir valores nos dias atuais tem sido um desafio 
para as famílias, e quando, por algum motivo os jovens não se enquadram nos padrões sociais estabelecidos, as mesmas são consideradas culpadas e incompetentes em sua função educativa. De certa forma, não apenas a sociedade, mas, muitas vezes, os próprios profissionais de saúde tentam localizar, na estrutura familiar, as dificuldades ou "problemas" que o adolescente apresenta.

Em nossa vivência profissional, temos observado que, apesar de toda dificuldade de pais e educadores em abordar as questões de sexualidade, parece já existir uma certa abertura e preocupação em canalizar a energia sexual dos jovens adolescentes de maneira ordenada, consciente e responsável.

Temos um longo caminho ainda a percorrer, muitos tabus e mitos a derrubar, mas pensamos que todo jovem tem o direito de ser orientado corretamente sobre sua sexualidade e esta deve começar no próprio lar, se estender à escola e a todas as instituições que façam parte da sociedade, e em especial nas instituições da área da saúde. Esse alicerce é importante para que o indivíduo seja capaz de resolver questões como: usar ou não anticoncepcionais, praticar ou não o aborto, entre outros, sem adquirir sentimentos de culpa, sem abalar sua integridade mental.

Dentro desse contexto bastante complexo, vamos situar a (o) enfermeira (o) como membro da equipe de saúde que tem papel fundamental na educação para a saúde de crianças e jovens. Mas, para que ela participe dessa transição de valores da atual sociedade emergente, ela precisa reavaliar sua escala de valores, nem sempre condizente com as necessidades atuais.

O sexo tem sido amplamente divulgado e debatido através de todas os meios de comunicação e cabe à (ao) enfermeira (o) conhecer os interesses reais dessas divulgações e os interesses econômicos camuflados nas entrelinhas.

É importante que a equipe de saúde conheça todos os caminhos trilhados por pais, professores e pela própria sociedade no que se refere à sexualidade, para que, de fato, possam colaborar na formação dos jovens de hoje, onde quer que eles estejam: na escola, hospital ou Unidade Básica de Saúde.

\section{SEXUALITY IN ADOLESCENCE: A BIBLIOGRAPHIC STUDY}

This is a bibliographical study that aimed at pointing out the history of sexuality as well as its cultural, social and religious influences. The goals were to find out in literature the causes of the difficulties faced by the actual men to approach themes related to sexuality mainly with their adolescent children that need this orientation in order to live a safier and healthier sexuality.

KEY WORDS: adolescence, sexuality

\section{SEXUALIDAD EN LA ADOLESCENCIA: UN ESTUDIO BIBLIOGRÁFICO}

Esta es una investigación bibliográfica en donde se buscó construir la historia de la sexualidad a través de los tiempos y las influencias culturales, sociales y religiosas en esa trayectoria. Nuestro objetivo fue el de buscar en la literatura, las raices de las dificultades enfrentadas por los hombres de nuestros dias, para abordar temas relacionados con la sexualidad, principalmente la de los hijos adolescentes que necesitan de esa orientación, para vivir una sexualidad con seguridad y también más saludable.

TÉRMINOS CLAVES: adolescencia, sexualidad

\section{REFERÊNCIAS BIBLIOGRÁFICAS}

01. ARRUDA, A. Sexualidade e informação: recado dos jovens paraibanos. In: PAIVA, V. (org). Em tempos de AIDS. São Paulo: Sumus, 1992. p. 139-144.

02. CABRAL, J.T. A sexualidade no mundo Ocidental. Campinas: Papirus, 1995.

03. CONCEIÇÃO, I.S.C. Educação sexual. In: VITIELLO, N. et al. Adolescência hoje. São Paulo: Roca, 1988. p. 71-76.

04. COSTA, M. Sexualidade na adolescência: dilemas e crescimento. 8. ed. São Paulo: L \& PM Editores, 1986.
05. ENGELS, F. A origem da família, da propriedade privada e do estado. Tradução Leandro Konder. 8. ed. Rio de Janeiro: Civilização Brasileira, 1982.

06. EGYPTO, A.C. et al. Papéis sexuais. In: BARROSO, C.; BRUSCHINI, C. Sexo e juventude: como discutir a sexualidade em casa e na escola. 4. ed. São Paulo: Cortez, 1991.

07. GAUDERER, C. A vida sem receitas. 2. ed. Rio de Janeiro: Objetiva, 1994.

08. GIDDENS, A. A transformação da intimidade: sexualidade, amor e erotismo nas sociedades modernas. Trad. Magda Lopes. 2. ed. São Paulo: Editora UNESP, 1993. 
09. GOLDBERG, M.A.A. Educação sexual: uma proposta, um desafio. 2. ed. São Paulo: Cortez, 1984.

10. KNOBEL, M. Orientação familiar. Campinas: Papirus, 1992.

11. LOPES, G.; MAIA, M. Desinformação sexual entre gestantes adolescentes de baixa renda. Rev. Sexol., v. 2, n. 1, p. 30-33, jan./julho 1993.

12. OSÓRIO, L.C. Adolescente hoje. 2. ed. Porto Alegre: Artes Médicas, 1992.

13. PARKER, R.G. Corpos, prazeres e paixões: a cultura sexual no Brasil contemporâneo. São Paulo: Best Seller, 1991. 295p.

14. RAPPAPORT, C. Encarando a adolescência. São Paulo: Ática, 1995.
15. SALES, J.M. de. Os pais dos adolescentes. In: VITIELlO, N. et al. Adolescência hoje. São Paulo: Roca, 1988. p.29-34.

16. SUPLICY, M. Conversando sobre sexo. 17. ed. Petrópolis: Edição da Autora, 1991. 407p.

17. ; EGYPTO, A.C.; BRANCO, C.C.; GONÇALVES, E.V. Sexo se aprende na escola. São Paulo: Olho d'água, 1995. 120p.

18.TIBA, I. Puberdade e adolescência: desenvolvimento biopsicossocial. São Paulo: Ágora, 1986. 236p.

19. UM MILHÃO de adolescentes dão a luz por ano no Brasil, diz IBGE. Folha de São Paulo, São Paulo, 08 març. 1991. Cotidiano, p.1. 